\title{
Continuidad y características emergentes en comunidades rural- indígenas. El caso de San Felipe Santiago, Estado de México
}

\author{
Georgina Gil Martínez \\ Egresada de la Licenciatura en Antropología Social, \\ en proceso de titulación. \\ catmargi1997@gmail.com \\ Felicitas Sánchez García \\ Egresada de la Licenciatura en Antropología Social, \\ en proceso de titulación. \\ papillina@hotmail.com \\ Laila Lorena Nieto Muciño \\ Egresada de la Licenciatura en Antropología Social, \\ en proceso de titulación. \\ lailanm08@hotmail.com \\ José Luis Arriaga Ornelas \\ jlarriagao@gmail.com \\ Dr. en Ciencias Sociales, Profesor-investigador titular en la \\ Miembro del Sistema Nacional de Investigadores (Nivel 1) del \\ Consejo Nacional de Ciencia y Tecnología de México.
} Facultad de Antropología de la Universidad Autónoma del Estado de México. Líder del Cuerpo Académico "Patrones culturales de las relaciones sociales"

\section{RESUMEN}

A partir de una aproximación etnográfica, el artículo documenta las características emergentes de una comunidad identificada como rural-indígena que en las últimas décadas ha experimentado cambios importantes. Su población ya no habla el idioma nativo, las actividades productivas se han desplazado hacia el comercio y los servicios, además de que hay una clara presencia de prácticas religiosas distintas al catolicismo tradicional. Estos cambios han derivado en una vida distinta, pero los habitantes no observan las características actuales de sus vidas desligadas del pasado. No es para ellos una sucesión de eventos divergentes, sino parte de una temporalidad en la que siguen presentes las cosas que ya no están. En su pensar colectivo hay ligas permanentes con las cosas que ya no se practican, pero que no están olvidadas.

Palabras clave: comunidades rural-indígenas, desplazamiento lingüístico, migración laboral, ambiente y articulación al entorno. 


\title{
Continuity and emerging characteristics in rural-indigenous communities. The case of San Felipe Santiago, State of Mexico
}

\begin{abstract}
Based on an ethnographic approach, the article documents the emerging characteristics of a community identified as rural-indigenous that has undergone important changes in recent decades. Its population no longer speaks the native language, productive activities have shifted towards commerce and services, and there is a clear presence of religious practices other than traditional Catholicism. These changes have led to a different life, but the inhabitants do not observe the current characteristics of their lives detached from the past. It is not for them a succession of divergent events, but part of a temporality in which things that are no longer present are still present. In their collective thinking there are permanent links with things that are no longer practiced, but that are not forgotten.
\end{abstract}

Keywords: rural-indigenous communities, linguistic displacement, labor migration, environment and articulation with the environment.

Artículo recibido: 05 de Abril 2021 Aceptado para publicación: 28 de Mayo 2021 Correspondencia: catmargil997@ gmail.com Conflictos de Interés: Ninguna que declarar 


\section{INTRODUCCIÓN}

Uno de los trabajos que más ha trascendido en la historia de las ciencias es el de Charles Darwin. Se le reconoce, sobre todo, por haberle colocado punto final al antropocentrismo y por haber prescindido de entidades creadoras (Dios/La Naturaleza) para explicar el origen del hombre. Pero, más de 150 años después de la publicación de sus trabajos cumbre, aún hay cosas que han sido insuficientemente exploradas. Una de ellas es la que Latour nos propone al sugerir que "nadie se opuso más que él (refiriéndose a Darwin y en especial a su trabajo L'Origine des espèces) a la idea de hundir todos los resultados dispersos de los seres vivos en el único medio universal anónimo y glacial de la Naturaleza” (2012a, 177). A partir de esta re-lectura a Darwin, Latour busca discutir la noción de "discontinuidad" para cuestionar la operación de alguna Idea, Providencia, Creación, Sentido o Ley que guíe la existencia de los seres vivos. Afirma: "para Darwin entre cada ser y el siguiente existe una discontinuidad vertiginosa que supone, en cada generación, una invención única y singular" (2012a, 178).

El presente artículo va a explorar esta discusión y a preguntarse cómo puede observarse dicha discontinuidad en el caso de las comunidades humanas. Va a presentar evidencia generada mediante una aproximación etnográfica en una comunidad rural-indígena en México y a interrogarse sobre los elementos que mantienen unidos a los grupos humanos, pese a la marcada discontinuidad entre generaciones. Para ello va a hechar mano de la noción de ambiente, en el sentido de creación que cada ser vivo hace a partir de elementos del entorno (Von Uexküll 2016; Lewontin 2017; Latour 2012a).

El trabajo toma como uno de sus puntos de partida lo que Darwin afirma: "para que un ser de apariencia simiana haya podido transformarse en hombre, es necesario que esa forma anterior, lo propio que las que consecutivamente le han seguido, hayan variado todas física y moralmente" $(1982,78)$. A través de este planteamiento, Darwin sugiere poner especial atención en las condiciones exteriores a que los seres vivos están sujetos. La evidencia con la que él cuenta para sugerir esto indica una "naturaleza diversa y mudable" en dichas condiciones exteriores; y afirma: "no cabe duda alguna en que el cambio en las condiciones provoca una extensión casi infinita de fluctuaciones variables, que hacen el conjunto de la organización plástica en algún grado" (Darwin 1982, 83).

La plasticidad aparece, pues, como un desafío cognitivo que el trabajo asume para lanzar la pregunta ¿Qué tanto puede fluctuar un grupo humano, una comunidad, un pueblo para 
que pueda seguirse hablando del mismo a lo largo de los años? Para responder a tal cuestión se asume que el reto mayor "es aceptar el desafío de comprender y dar cuenta de las mutaciones, la evolución y la creciente complejidad como posibilidades. Cuando se renuncia a ver únicamente la estabilidad estructural, la incertidumbre puede servir heurísticamente en la investigación para documentar procesos en curso (Arriaga y Marcial 2017, 42). La relevancia de realizar esto es apreciar cómo los ajustes, acuerdo y arreglos locales construyen un tipo de vida social que es posible conocer, sin que se tenga que asumir apriorísticamente la existencia de estructuras monolíticas que lo expliquen todo y de las que sólo haya que explicar sus cambios.

La adaptación, desde un punto natural o biológico, es el proceso de cambio evolutivo mediante el cual el organismo procura una solución al problema que se le presenta (Lewontin 2017). Desde el ámbito social, puede plantearse pertinentemente una pregunta: ¿si en una comunidad X, a lo largo de unas cuántas décadas, cambian la lengua que hablan sus habitantes, la actividad productiva de la mayoría de ellos y hasta la práctica religiosa entre grupos muy considerables a su interior, puede seguirse hablando de una misma comunidad? ¿Puede tomarse como un proceso evolutivo de la misma? Quizá como principio teórico tendría que aceptarse que el punto de partida no debería ser un estado de cosas acabado y definitivo, del que pueden desprenderse explicaciones para los comportamientos de los individuos, sino que puede adoptarse como referente inicial la capacidad de documentar los "ajustes" que están dando vida a lo social: "no como un dominio especial, un reino especifico o un tipo de cosa particular, sino como un movimiento muy peculiar de reasociación y de reensamblado" (Latour 2008, 21), lo cual devuelve a su carácter de contingente el hecho social.

En el ser humano, el proceso de adaptabilidad se lleva a cabo como respuesta al entorno: las sociedades se adaptan tanto al medio natural como sociocultural, decía Steward (1955). Entonces, en el caso de los grupos humanos, también puede haber respuestas al entorno tomadas de manera colectiva. Esas respuestas pueden tomarse como nuevas conexiones entre individuos y de estos con su entorno. Los ajustes tendrían que ser vistos como procesos por medio de los cuales los individuos se articulan al entorno, que se catalizan a través de su cultura, permitiendo que el individuo se articule adecuadamente (Subuyuj 2013), aun cuando en el camino se vayan quedando algunas cosas. Podría pensarse que, en la lucha por la supervivencia los grupos sociales tienen que decidir entre conservar ciertos 
rasgos culturales que los identifican o dejarlos con la finalidad de sobrevivir. Hay características de la cultura que son afectadas por los ajustes (Velasco 2002), pero hace falta preguntarse si desaparecen automática y definitivamente o son sujetas a nuevas formas de organización del universo cotidiano en temporalidades muy particulares.

La noción de temporalidad es muy importante porque alude al "modo de ordenamiento para relacionar elementos" (Latour 2012b, 112). Esto remite a una muy importante consideración sobre el principio bajo el cual se rige ese ordenamiento. Si el principio es el del pasado superado, la temporalidad se muestra como un pasaje ordenado y sistemático del tiempo, una flecha irreversible, un flujo continuo que va del porvenir hacia el pasado, típico del pensamiento moderno, diría Latour. Pero, él mismo sugiere que, si aguzamos la mirada e identificamos otras maneras de reagrupar los tiempos, por ejemplo, a lo largo de una espiral y no ya de una línea, "realmente tenemos un futuro y un pasado, pero el futuro tiene la forma de un círculo en expansión en todas las direcciones y el pasado no está superado sino retomado, repetido, rodeado, protegido, recombinado, reinterpretado y rehecho" (Latour 2012b, 112-113).

Contingencia, fluctuaciones, adaptación, reorganización constante, son elementos que van a aparecer con frecuencia a lo largo de este texto para, a la luz de los datos generados en una comunidad que ha experimentado una discontinuidad vertiginosa, preguntarse acerca de las posibilidades argumentativas, vivenciales, existenciales y emotivas (Pérez-Taylor 2002) de la gente que ahí vive, que pertenece a generaciones distintas (entre las que resultan evidentes algunas fluctuaciones muy importantes, debido a decisiones, acciones y movimientos únicos y singulares que el trabajo de campo permitió conocer en la propia voz de los habitantes del lugar de estudio), pero que se mantiene viviendo comunitariamente gracias a la temporalidad particular que alimentan de forma colectiva. Este ejercicio nos ofrece un buen medio de contraste para enfrentar a dos metáforas muy comunes: la sociedad como organismo, que nos presenta la imagen de una totalidad "natural", que por mucho tiempo dominó las teorías sociológicas y antropológicas (Dubet y Martuccelli 2000, 43); así como la metáfora de la flecha irreversible del tiempo, propia de la temporalidad moderna (Latour 2012b).

\section{MÉTODO EMPLEADO}

De acuerdo con el enfoque adoptado, el trabajo también atendió a la sugerencia del propio Latour (2008) en el sentido de que lo más conveniente es "comenzar en medio de las 
cosas": ubicarse en el sitio donde se pueda ver que los procesos están ocurriendo. Por ello es que el trabajo de campo es el procedimiento que se privilegió. Se acudió durante varias semanas a la comunidad de San Felipe Santiago, municipio de Jiquipilco, Estado de México. Se trata de una comunidad otomí que se encuentra situada en un pequeño valle cenagoso, a escasos 100 kilómetros de la Ciudad de México, capital del país, en la que de manera más o menos reciente inició un proceso de transformación que se consideró necesario documentar.

La aproximación etnográfica buscó conocer de manera directa las estrategias que se llevan a cabo dentro de las familias de dicha comunidad para la subsistencia. Observar cómo viven su día a día, preguntar, grabar, fotografiar y tomar nota de las actividades económicas que ejecutan y de la organización grupal, es lo que se hizo al estar ahí. También interesaba saber acerca del desplazamiento lingüístico que se experimenta en el caso de la lengua otomí y la presencia de prácticas religiosas distintas al catolicismo desde hace varias décadas, sobre todo del movimiento pentecostal.

En una primera etapa del trabajo se tuvo contacto con 21 familias de la comunidad para, en un segundo momento, seleccionar a 7 de ellas. La elección fue determinada por sus características, relacionadas con tendencias presentes en este lugar, ilustrativas del proceso de adaptación y re-configuración del ambiente en el que se desarrollan. Se trató de familias de tipo "tradicional" para la cultura Otomí, es decir, de "un grupo que vive bajo el mismo techo y que puede considerarse un subconjunto del grupo doméstico (...) que se integra por todos los miembros del grupo que tengan afinidad o consanguinidad, sin que necesariamente coman, duerman o vivan en la misma casa" (Sandoval 1997, 52).

Las familias tomadas en cuenta fueron elegidas por ser notorio en ellas la presencia medidas adaptativas que han llevado a cabo. Cada grupo familiar fue visto como una disposición compleja, con clara tendencia a la dispersión, con decisiones se antojarían azarosas pero que, como se verá con los datos, logran autorregularse para su conservación más o menos estable. De modo que, dentro de esta aparente indeterminación, prevalece a pesar de todo cierto orden familiar y social.

Se convivió y conversó con estas familias en el verano del año 2019. Se realizaron registros visuales y de audio. También se observaron y documentaron actividades, rutinas, interacciones y actores participantes. Se puso énfasis en tres cosas principalmente: organización de la familia, actividades económicas, uso de la lengua otomí y afiliación 
religiosa. Las conversaciones buscan, sobre todo, la perspectiva diacrónica de los actores: qué hacían antes y qué hacen ahora, de qué vivían y cómo lo consiguen ahora, en qué creen y cómo es su vida bajo esas creencias, entre otros tópicos. Los datos se despliegan de tal manera que permiten ver cómo puede discutirse aquella idea muy extendida de que las comunidades indígenas son muy conservadoras y que cambian muy lentamente y oponen resistencia a los cambios. "Sin embargo, al poner énfasis en los aspectos económicos, se considera que, si éstos son modificados, los grupos se ven obligados a sufrir transformaciones radicales" (Sandoval 1997, 52).

\section{RESULTADOS}

La comunidad de San Felipe Santiago pertenece al municipio de Jiquipilco, ubicado al noroeste del valle de Toluca, en la zona centro-sur de México. De acuerdo con el Plan de Desarrollo Municipal (H. Ayuntamiento de Jiquipilco 2019) su población aproximada es de 3, 200 habitantes, de los cuales $45.3 \%$ son hombres y $54.7 \%$ mujeres. De este total, $67.4 \%$ es población indígena, perteneciente al pueblo Otomí. Sin embargo, sólo uno de cada cuatro (25.7\%) habla la lengua y/o es bilingüe; la gran mayoría de sus pobladores hablan español.

Por ubicarse en el altiplano mexicano, este lugar se caracteriza por un clima templado subhúmedo, con lluvias en verano y escasas en invierno. La calle principal de San Felipe Santiago destaca por su amplitud y por contar con un camellón en medio; aparte de ser la entrada a la comunidad y atravesarla, también es parte de la ruta que comunica con otras comunidades. Al inicio de esta calle se encuentra una Escuela Primaria y atrás de la misma se ubica un campo de fútbol, en donde se desarrollan las ligas locales (varonil y femenil, que juegan, sobre todo, los días domingo). En la localidad la presencia de instituciones escolares se remonta al año 1945, pero hoy se cuenta con oferta educativa hasta el nivel medio superior, pues, aparte de la Primaria ya referida, se asientan en el lugar la Escuela Secundaria Técnica No. 82 "Díaz Mirón” y la Escuela Preparatoria oficial No. 58.

Los días con más movimiento en las calles son los sábados, pues se desarrolla el tianguis local. Desde muy temprano se colocan los puestos de comida a lo largo de la calle principal; se vende barbacoa, carnitas, tacos y hay también puestos de frutas y verduras. Todo esto es adicional a los comercios fijo de carnicería, panadería, pollería, recauderías, ferretería, zapatería, varios molinos de nixtamal, tiendas de abarrotes, farmacias, consultorios 
médicos, carpinterías, mecánicos, entre otros. La mayoría son negocios familiares. Destacan varios establecimientos que ofrecen tortillas "hechas a mano"1.

Aun cuando el municipio de Jiquipilco, al que pertenece la comunidad, tiene como actividad principal la agricultura, en San Felipe Santiago la mayoría de las personas combinan el trabajo agrícola con otras actividades, que van desde el comercio local hasta la albañilería, incluyendo también el trabajo doméstico, entre otros. De igual manera hay una importante presencia de migración hacia la Zona Metropolitana de Toluca, Ciudad de México (mayoritariamente) e inclusive a los Estados Unidos de Norteamérica.

En San Felipe Santiago existe un templo católico (en la zona centro del lugar), pero en distintos puntos de la localidad suman siete templos del movimiento pentecostal. Estos últimos destacan por estar edificados más recientemente, con material y acabados de mayor calidad que el templo católico. Además, las familias con mayor prosperidad económica son practicantes miembros de esta iglesia, de origen norteamericano.

Ya en un recorrido por toda la comunidad se aprecia que alrededor de la mayoría las casas hay cultivos de maíz (de autoconsumo) y se ve con relativa frecuencia que las familias aún tienen aves de corral, como gallinas, guajolotes y patos (también para autoconsumo). Se pudo observar que las mujeres aún mantienen la tradición de elaborar las tortillas de maíz en su casa, para lo cual utilizan como combustible el zacate, (tallos de maíz seco) y leña extraída de las zonas boscosas aledañas. Uno de los aspectos que se registraron con más frecuencia estando en el sitio es que, dentro de las actividades de las familias, aparte del cultivo del maíz, tienen un negocio propio, en el cual la mayoría de las veces trabaja toda la familia. El negocio o comercio familiar puede ser fijo o ambulante, puede estar en la localidad o fuera de ésta. En ocasiones llevan a cabo varias actividades a la vez. También existen casos en los que trabajan como jornaleros dentro del municipio o en zonas aledañas. El entorno, en su sentido más amplio, no ha dejado de cambiar para los habitantes de San Felipe Santiago. Sus habitantes han venido tomando decisiones relacionadas con esa dinámica, buscando una mejor articulación al entorno. Lo que se pudo documentar a partir de la aproximación etnográfica es que estas familias toman decisiones trascendentes en función de asuntos coyunturales, creando -como sugerirían Von Uexküll (2016), Lewontin

\footnotetext{
${ }^{1}$ Para un panorama más amplio de este tipo de trabajo emergente en México, sobre todo en zonas en proceso de urbanización, véase Encino, Flores, Miranda y Arriaga: Tortillas "hechas a mano": trabajo domiciliario femenino emergente en el barrio de San Martín, Malinalco, Estado de México (2020).
} 
(2017) y Latour (2012)- una especie de "burbuja" que extraería de ese entorno cierto número de señales que juzgan pertinentes para articular su vida.

Ya sea el cambio de lengua otomí por el español, la adopción de la religión pentecostal y el hecho de que tienen que salir a desempeñar actividades diversas, coloca a estas familias en una especie de indeterminación constante, un proceso totalmente estocástico. Las decisiones tomadas respecto a la familiar, la religión o la lengua, que se van a exponer a continuación producto del trabajo de campo, casi siempre son pensadas "desde afuera" como alteraciones de las estructuras rígidas. Sin embargo, en San Felipe Santiago se puede ver que estas estructuras están en constante fluctuación, siempre en movimiento, transformándose rápida e impredeciblemente.

\section{Desplazamiento lingüístico}

Una de las medidas más trascendentes llevadas a cabo por estas familias, a partir de la inevitable interacción con otros grupos sociales de su entorno, fue aprender a hablar el español y dejar de hablar su lengua materna, el otomí. El español empezó a sustituir a la lengua materna de esta comunidad a medida que se fue haciendo necesario convivir con personas externas que llegaban al lugar, como los profesores de las escuelas:

En la comunidad todos hablaban otomí. Éramos muy pobres, no se usaban los zapatos... Cuando empecé a ir a la escuela me daba harta pena, porque no sabía el castellano que le decían. El maestro me regañaba porque hablaba en otomí... las clases eran en puro español... Me daba trabajo hablar el español...cuando llegaba a venir alguien de fueras, de los que hablaban español, yo me escondía entre las (matas) del maíz...decía yo: hijo ¿y si me habla? ¿qué le voy a decir? Me daba pena que me preguntara algo en español y yo no le supiera contestar (Amadeo, 77 años).

Pero, sobre todo, el desplazamiento lingüístico es relacionado por los mismos habitantes con el hecho de que lugareños empezaron a salir a las ciudades a trabajar.

Desde muy chica salí a trabajar...casi niña me fui a la Ciudad de México, ahí trabajaba con otras muchachas... Trabajábamos en unas tortillerías, se hacían con la prensa, no como aquí que se hacían a mano. Las otras muchachas me enseñaron a hacer tortillas...me enseñaron también a que hable yo el español... Mi esposo y yo todavía hablamos el otomí...mis 
hijos ya poco lo hablan; sí lo entienden, pero sus hijos, o sea mis nietos, ya no lo hablan y lo entienden muy poco... Mis papás hablaban otomí, hablaban poco español (Modesta, 72 años).

Uno de los principales obstáculos que enfrentaron los migrantes para dirigirse a la ciudad de México u otras ciudades a donde migraron por cuestiones laborales fue el del idioma. El índice de monolingüismo en hñäñho (otomí) era elevado para mediados del siglo pasado; sólo las personas que sostenían relaciones con el exterior conocían, al menos, lo elemental de la lengua castellana para comunicarse. Hay dos elementos engarzados en el testimonio de los informantes acerca de este proceso, que relacionan migración laboral con el uso de su lengua: por un lado, la imperiosa necesidad de conseguir el sustento y para ello interactuar con hablantes de español; y, por el otro, la discriminación por hablar su lengua fuera de la comunidad. Como resultado de esto los padres de familia incluso prohibieron a sus hijos que hablaran su lengua original:

Cuando era yo joven me fui a trabajar a Gualupita, en una casa haciendo el aseo. Fue muy feo, porque hablaba puro otomí y se burlaban. Luego, cuando fui a trabajar a la Ciudad, en México, me hacían burla también, me decían guarina... Me sentía muy mal, sufrí muncho, por eso no quise que mis hijos hablaran otomí, ya no les enseñé, para que no los trataran como a mi, que no sufrieran como yo. Ni mis hijos ni mis nietos hablan otomí, español nada más (Juliana, 63 años).

En nuestro caso, pues le diré que nuestros papaces nos pegaban cuando hablábamos otomí, nos daban un manotazo: ¡Órale!, no querían que lo habláramos. Decían: ¡habla español! ¡Otomí no hables! De mis cuatro hijos y seis nietos que tengo, ninguna habla el otomí, todos hablan el español, como trabajan en la ciudad, también por eso, ¿cómo le diría yo?... Lo que necesitan es hablar español (Luis, 73 años).

Es preciso señalar que, aunque la mayoría de las generaciones jóvenes de la comunidad ya no hablen otomí, los adultos mayores que viven en la comunidad aún siguen comunicándose entre ellos en su lengua originaria, pero sobre todo en el espacio privado:

Nosotros hablamos puro otomí, nomás que cuando vienen personas de fuera hablamos el español. Mis abuelitos y mis papás ya no viven, pero ellos hablaban otomí. Mi mamacita aprendió el español ya muy grande, 
yo lo aprendí desde niña... luego como me fui de niñera a México, ahí hablaba puro español... Cuando me casé, me regresé a mi pueblo con el galán y seguimos hablando el otomí entre nosotros. Cuando no hay otra gente lo hablamos (María, aproximadamente 70 años).

La lengua otomí ha sido relegada al espacio doméstico, a los sectores de mayor edad y está desvinculada totalmente de las actividades económicas y hasta religiosas. Tiene un lugar marginal y de riesgo, al menos en esta comunidad.

\section{El tema religioso}

Ya Durkheim aseguraba que las sociedades tienden a organizarse mejor desde el aspecto religioso, siendo este uno de los principales móviles para la unión o separación de determinados grupos humanos (1982). Lo que pudo observarse en el caso de San Felipe Santiago es que hay un evidente desplazamiento hacia el movimiento pentecostal, en detrimento del catolicismo. Los testimonios recabados son en el sentido de que "hay ventajas en este nuevo culto", ya que logran "vivir en una mayor armonía”, "hay más apoyo entre ellos", además de que se "ven disminuidos los vicios", principalmente el alcoholismo -dicen.

Desde hace varios años vinieron un grupo de "gringos" a la comunidad, a conocer nuestra cultura, a quitárnosla, para eso nos dividieron primero. Enseñaron la religión a algunas personas de aquí del pueblo y así se fue regando... Queriendo hacernos un mal, nos hicieron un bien; la gente tomó lo bueno de la religión que ellos trajeron. Se tomó lo que sirve: hay más unidad con las familias, la gente se dedica a trabajar y no a emborracharse... hay en el pueblo muchachos vagos, que se dedican a tomar...ellos son católicos...ya hasta se conoce quienes son, de qué familias y todo (Abel, 64 años).

El movimiento pentecostal, además de servir como un estímulo para llevar a cabo las acciones necesarias que permitan la supervivencia, a los ojos de los propios informantes, cumple con un papel regulador de las acciones de los individuos, ya sea a nivel familiar o social, y de ello se derivan varios aspectos más, como puede ser el económico, de relaciones familiares, laborales, entre otros mecionados por ellos mismos. En San Felipe Santiago el pentecostalismo, que en sus inicios empezara modestamente, hoy se presenta como un 
movimiento religioso importante, que va ganando terreno rápidamente, según los testimonios.

Yo y mi familia somos de la religión pentecostés. Yo desde joven, como desde el cuarenta y cinco se empezó a predicar la religión pentecostés aquí en San Felipe; empezó un señor de nombre Macedonio Gil, le siguió el señor Cipriano Apolonio Morales. Él se acercó porque estaba enfermo su hijo, como se curó, entonces empezó a predicar él también. Empezó con sus familiares, sus vecinos (y) así se siguió. Luego se fueron construyendo los templos, poco a poco... En un principio la gente de San Felipe no estaba de acuerdo con la nueva religión... una vez hubo un pleito grande entre católicos y pentecostales, los católicos lincharon a un pentecostés. Se presentó la denuncia en Jiquipilco pero no se hizo nada, luego se fue a poner denuncia a Toluca, en la procuraduría. Se llegó al acuerdo de no molestarse entre católicos y la religión de nosotros. Desde ahí ya se pudieron hacer las celebraciones sin problemas, se fueron construyendo los templos...ya hay como siete, más o menos (Brígido, 88 años).

\section{El ámbito económico}

El municipio de Jiquipilco en lo general y su comunidad de San Felipe Santiago en lo particular, desde los años cuarenta del siglo XX fueron identificados como sociedades agrícolas. Ello debido al reparto de tierras llevado a cabo a partir de 1936, por el entonces presidente de la República Lázaro Cárdenas del Río. La tierra que se repartió por esta zona pertenecía a la hacienda de Sila, pero, tras la Revolución y las reformas jurídicas que ella trajo, las tierras pasaron a manos de los campesinos otomíes que se desempeñaban como peones de la misma hacienda.

El anhelo de lograr una vida mejor -coinciden algunos informantes-, que se consiguiera fuera de la comunidad, los enfrentó con la discriminación cotidiana, por ser diferentes. La mayoría de los informantes dicen no sentirse cómodos trabajando fuera de su lugar natal, pues les hacía falta "algo", la tranquilidad habitual del campo. Y, aunque por estrategia de supervivencia llegaban a las ciudades, siempre se sintieron ajenos a ésta, de modo que terminan regresando a su lugar de origen, con los suyos: 
Cuando me casé, yo y mi marido nos fuimos a trabajar a la Ciudad de México, él trabajaba de cargador y yo hacía la limpieza en una casa... Luego nos regresamos pa'cá, pal pueblo, nuestro pueblo... ¿A dónde voy?, este es mi rancho...aquí lo que se come son frijoles, quelites y nopales... Aquí antes no había tantos dulces no refrescos" (María, aproximadamente 70 años).

Mi esposo y yo nos conocimos en México (Ciudad de México), allá trabajábamos los dos...vivíamos en la casa del papá de él...pero mejor nos regresamos al pueblo y nos pusimos a vender cosas y criar animales (Lilia, 41 años).

Yo aprendí a tejer los suéteres de lana gracias a un amigo... De joven me fui a trabajar a la Ciudad de México... Fíjese que ese amigo era de Gualupita, una vez me invitó a su pueblo. Ocho días estuve yo ahí, en su casa y vi cómo tejían en sus bastidores... Sí aprendí bien. Empecé a hacer lo mismo y a vender... Llegamos a tener mi esposa y yo un puesto en una placita de esas que hay en los centros comerciales. Luego se enfermó mi esposa y perdimos el lugar; nos tuvimos que ir a vender a las plazas. Vamos a Gualupita, o a veces nos vamos a Santiago Tianguistenco... Antes vendíamos mucho, ahora ya no, entre mi esposa y yo llegamos a hacer como dos piezas por semana... Como también tenemos que estar al pendiente de nuestros cuatro nietecitos, ya no nos alcanza el tiempo... Mi esposa hace el aseo en el kínder; va tres días a la semana (Luis, 73 años).

En esta como en la mayoría de comunidades rurales el trabajo y la familia están articulados, son interdependientes y se complementan, se influyen entre si. No es posible que se estudien aisladamente (Riquelme, Rojas y Jiménez 2012). Inclusive la migración (que en la comunidad se volvió más común a partir de la década de los ochenta del siglo pasado) es parte de una decisión colectiva tomanda por la familia en tanto unidad de producción y consumo.

Los adultos jóvenes, en el rango 30 a 40 años, son quienes más se "aventuran” y salen del hogar con la intención de prosperar económicamente, ya sea de una manera personal, o darle lo mejor a la propia familia. En algunos casos, incluso, justifican la decisión de salir 
diciendo que "el lugar (la comunidad) les aburre". Entonces -dicen- van "en busaca de aventuras", lo cual se vuelve posible en esta comunidad, porque migrar es una acción recurrente en las familias, ya por al menos tres generaciones.

En la Ciudad de México hacíamos de todo, cuando no trabajábamos en las casas de los ricos, vendíamos queso y crema en las plazas, en los mercados. Llevábamos la mercancía en una canasta, lo ofrecíamos a la gente e íbamos caminando... De regreso, en el pueblo, vendíamos lo que se pudiera, Aquí en las plazas cercanas, en Ixtlahuaca o en Jiquipilco... Llegamos a vender pollo, luego nos pusimos a vender productos de limpieza como cloro y jabón, lo llevábamos de pueblo en pueblo... Con el dinero que fuimos ahorrando, compramos un terreno donde fincamos nuestra casa... Compramos también un tráiler y salíamos a trabajar a las fiestas; él la hacía de animador y yo atendía la cantina (Lilia, 41 años). Actualmente trabajo en una fábrica, en Ixtlahuaca; los días que no voy a la fábrica estoy aquí, en la tienda... Tengo una tienda en uno de los locales que construí, gracias al dinero que ahorré cuando estuve trabajando "de mojado" en los Estados Unidos. Me fui en el 2011, nos fuimos como veinte, sólo llegamos tres a Estados Unidos... Junté un dinero y me regresé, me metí a trabaja porque me aburría, ya que la localidad es muy tranquila... vivo solo...entonces me metí a la fábrica por convivir...para conocer, así convivo con mis compañeros y se puede salir con alguien, una mujer o.... pues, sí, así (Servando, 38 años).

Entre los testimonios recolectados en campo deben destacarse las decisiones económicas (como migrar o emprender nuevas acciones para el sustento) alejadas ya de la vida campesina (sembrar la tierra, criar animales, etc.) y, al mismo tiempo, las decisiones colectivas, tomadas por la familia (como unidad productiva y de consumo) para resolver sus problemas económicos, destinando parte de la fuerza de trabajo de esta unidad a actividades comerciales, servicios (dentro y fuera de la localidad) y dejando a otra parte en la casa para cuidad la siembra y los animales.

Soy operador de un tractor, el dueño es mi primo, pero me lo da a trabajar.

Soy chofer. También tengo una podadora con la que hago trabajitos a los mismos de aquí... En las noches me voy a vender papas, aquí en la calle 
principal, junto a la escuela, me ayudan mi mamá y mi tía. Entre los tres armamos el puesto, así es más rápido; para recoger, igual. Les digo: si queremos comer, hay que darle, hay que trabajar (Jesús, 50 años).

Mi esposo trabaja en una fábrica de productos químicos en la Ciudad de México, aunque también se dedica al campo en las temporadas, cuando hay que sembrar el maíz... Cuando se cosecha se viene a trabajar acá. Yo abro la tienda todos los días, desde hace quince años... En ocasiones nos vamos a vender a las ferias, vendemos de todo; a veces vendemos pambazos, elotes, cocteles de fruta, refresco, cervezas. Vendemos lo que se pueda, hasta zapatos hemos llegado a vender...cuando hay que trabajar en el campo yo también ayudo, aquí las mujeres ayudamos a todo (Carmen, 41 años).

Llevo alrededor de veinte años con la lonchería, es como la tienda escolar, de aquí de la Preparatoria. Cuando se abrió la prepa, yo entré de velador...empecé a vender desayunos en una mesita y una lona, era poco lo que tenía. Poco a poco fui mentido más productos hasta que se hizo el local... Mi hijo se fue a Estados Unidos en el noventa y seis, después de siete años vino de visita, luego se regresó de nuevo... También trabajo en el campo cuando hay que sembrar, se cultiva maíz, es de regadío: se riega por las noches, es por turno, paga uno cien pesos por hectárea que necesite regar... Tengo algunos borregos, pollos también y un huertito; aquí se dan los ciruelos, las manzanas y los duraznos... Se tiene lo necesario para vivir (Abel, 64 años).

A decir de los informantes las decisiones que han tomado históricamente no necesariamente son producto de un plan, más bien resultarían coyunturales: se actúa de acuerdo a como se van presentando las situaciones; quizá de manera imprevista. De manera reiterada se notó que las mujeres, además de los quehaceres del hogar, ayudan en los trabajos del campo, en la época de siembra y cosecha del maíz; también se hacen cargo del cuidado de los animales domésticos y en muchas ocasiones ayudan vendiendo algún producto por su cuenta o apoyando el esposo.

"Soy la mayor de seis hermanos... Antes de casarme ayudaba a mis padres en los trabajos del campo (y) cuando trabajaba les compraba 
algunas cosas que necesitaban mis hermanos... Todavía de casada me piden opinión para asuntos que tienen que ver con mis hermanos menores; siempre estoy al pendiente... Hace dos años que vendo pollo aquí en el local... Cuando era soltera trabajaba de empleada doméstica. Ya de casada le ayudo a mi esposo: engordamos cerdos para venderlos... Cuando hay que trabajar en la milpa, también ayudamos las mujeres... A mi bebé la tengo aquí en el negocio, estoy aquí en la tienda, llego temprano, me voy como a las siete de la tarde... Aparte del pollo tengo el molino de nixtamal... Mi esposo trabaja en la albañilería" (Aida, 30 años)

Cuando es tiempo de siembra, ayudo a mi tía con sus tierras, después vamos con lo mío. Cuando es tiempo de tirar el fertilizante, lo hacemos entre los dos. El mata hierba lo pongo yo, ahí ya no me ayudan... En lo que ellas pueden siempre me ayudan... Cuando me accidenté manejando un camión de carga, mi mamá y mi tía me ayudaron mucho...me llevaban de comer a la cama. Nos tenemos que echar la mano entre familia (Jesús, 50 años).

Hago bordados en diferentes tipos de tela, puede ser lana, o manta. El bordado puede ser en servilletas, cojines... Los manteles se los hago del tamaño que me pida el cliente y con las figuras que ellos elijan. Una de mis hijas, la casada, también sabe bordar; ella me ayuda a bordar (y) vamos a vender a Jiquipilco, a veces a Ixtlahuaca. También los vecinos nos hacen pedidos de servilletas, principalmente para cuando hacen fiestas, ya sea de bodas o quince años... Yo no sé usar el telar, la que sabe es mi mamá. Anteriormente se hacía mucho el mecapal tanto de ixtle como de hilaza. (Mi mamá) trabaja las fajas y los ayates; eso sí, tienen que ser sobre pedido. En el caso de las fajas, pueden ser lisas o bordadas, las bordadas cuestan más. Ella (también) hace los costales, de esos que se usan para las mazorcas, los hace con ixtle de los magueyes (Alicia, 55 años).

En la comunidad y sobre todo algunas de las familias entrevistadas, se presentan casos en los que los abuelos tienen que hacerse cargo de los nietos mientras los hijos salen a trabajar. 
No por eso dejan de lado sus actividades del campo o cualquier otro que tenga que ver con alguna forma de conseguir el sustento propio.

Tengo dos hijas, una tiene tres niños, dos van en la secundaria y uno en la primaria. El más chiquito es de mi hija la menor... Nos encargamos (su esposa y él) de los cuatro. Mis hijas son madres solteras, trabajan en México, trabajan en casas haciendo el aseo (y) vienen cada ocho días a ver a sus hijos, a traerles dinero para lo que lleguen a necesitar (Luis, 73 años)

Las siete familias seleccionadas para el estudio tienen ciertas características generales que se concentran en la Tabla 1

Tabla 1

\begin{tabular}{|c|c|c|c|c|c|}
\hline Familia & $\begin{array}{l}\text { Estructura } \\
\text { familiar }\end{array}$ & Lengua & Economía & Religión & Agricultura \\
\hline (1)Familia & $\begin{array}{l}\text { extensa. } \\
\text { Los hijos con } \\
\text { familia tienen } \\
\text { su propia casa, } \\
\text { pero, viven } \\
\text { cerca de la casa } \\
\text { de los padres. }\end{array}$ & \multirow{5}{*}{$\begin{array}{l}\text { Adultos de la } \\
\text { tercera edad } \\
\text { que hablan la } \\
\text { lengua } \\
\text { otomí, junto } \\
\text { con sus hijos } \\
\text { mayores. Las } \\
\text { personas } \\
\text { mayores son } \\
\text { de alrededor } \\
\text { de } 50 \text { años } \\
\text { que aún } \\
\text { hablan el } \\
\text { otomí, los } \\
\text { hijos lo } \\
\text { entienden, } \\
\text { pero pocos lo } \\
\text { hablan, } \\
\text { mientras que } \\
\text { los nietos se } \\
\text { ha perdido el } \\
\text { dominio de } \\
\text { hablarlo }\end{array}$} & \multirow{5}{*}{$\begin{array}{l}\text { Los adultos se } \\
\text { dedican aún a } \\
\text { los trabajos del } \\
\text { campo mientras } \\
\text { los hijos y los } \\
\text { nietos salen a } \\
\text { buscar medidas } \\
\text { de subsistencia, } \\
\text { ya que en las } \\
\text { grandes } \\
\text { ciudades o en } \\
\text { las plazas } \\
\text { locales, el } \\
\text { comercio es lo } \\
\text { más practicado, } \\
\text { seguido de la } \\
\text { albañilería (en } \\
\text { el caso de los } \\
\text { hombres) y el } \\
\text { empleo } \\
\text { doméstico (para } \\
\text { el caso de las } \\
\text { mujeres). }\end{array}$} & \multirow{5}{*}{$\begin{array}{l}\text { En la } \\
\text { comunidad se } \\
\text { practicaba } \\
\text { únicamente la } \\
\text { religión católica } \\
\text { pero, alrededor } \\
\text { de } 1950 \text { llegó la } \\
\text { religión } \\
\text { pentecostés que } \\
\text { poco a poco fue } \\
\text { ganando } \\
\text { terreno. En la } \\
\text { actualidad la } \\
\text { mayoría de las } \\
\text { familias } \\
\text { practican la } \\
\text { nueva religión, } \\
\text { (sobre todo las } \\
\text { familias más } \\
\text { pudientes) }\end{array}$} & \multirow{5}{*}{$\begin{array}{l}\text { Anteriormente } \\
\text { era su principal } \\
\text { medio de } \\
\text { subsistencia, en } \\
\text { el que los } \\
\text { cultivos eran } \\
\text { variados, } \\
\text { además de } \\
\text { maíz, se } \\
\text { cultivaba } \\
\text { avena, trigo, } \\
\text { frijol, chícharo, } \\
\text { calabaza etc. } \\
\text { En la actualidad } \\
\text { se cultiva } \\
\text { solamente el } \\
\text { maíz para } \\
\text { autoconsumo. } \\
\text { Debido que su } \\
\text { venta no cubría } \\
\text { las necesidades, } \\
\text { la gente tiene }\end{array}$} \\
\hline $\begin{array}{l}\text { (2) Familia } \\
\text { García }\end{array}$ & $\begin{array}{l}\text { Familia } \\
\text { extensa. Viven } \\
\text { ambos padres, } \\
\text { con hijos y } \\
\text { nietos }\end{array}$ & & & & \\
\hline $\begin{array}{l}\text { (3)Familia } \\
\text { García } \\
\text { Hernández }\end{array}$ & $\begin{array}{l}\text { Familia } \\
\text { nuclear. Viven } \\
\text { ambos padres, } \\
\text { con hijos y } \\
\text { nietos }\end{array}$ & & & & \\
\hline $\begin{array}{l}\text { (4) Familia } \\
\text { Solís }\end{array}$ & $\begin{array}{l}\text { Familia } \\
\text { nuclear. }\end{array}$ & & & & \\
\hline $\begin{array}{l}\text { (5) Familia } \\
\text { Juárez }\end{array}$ & $\begin{array}{l}\text { Familia } \\
\text { nuclear. Un } \\
\text { matrimonio con } \\
\text { un hijo. Y el } \\
\text { resto viven } \\
\text { fuera de casa. }\end{array}$ & & & & \\
\hline
\end{tabular}




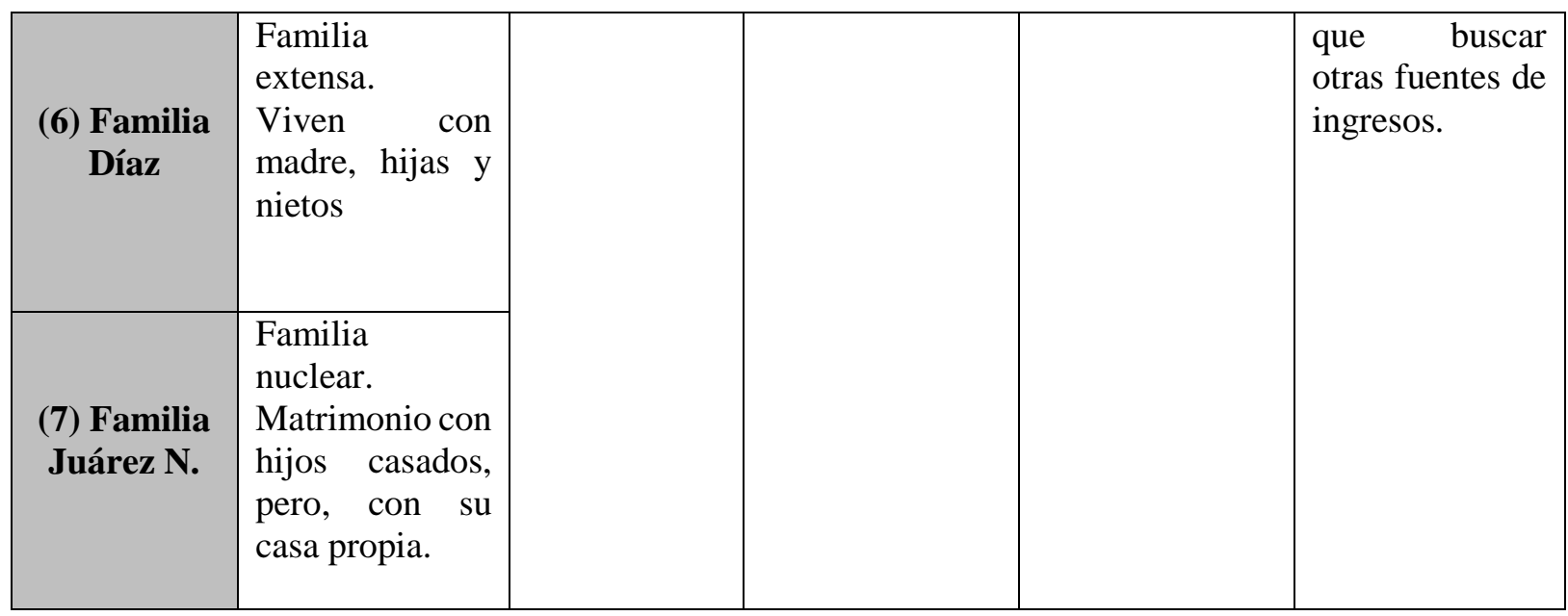

Fuente: Elaboración propia con datos de trabajo de campo 2019

En la siguiente tabla (Tabla 2) se muestran otros datos cualitativos que complementan los datos primarios consignados en la Tabla 1. Buscan dar una idea más amplia sobre lo que ocurre al interior de las familias tomadas para el estudio.

\section{Tabla 2}

\begin{tabular}{|c|c|c|c|c|}
\hline Familia & Migración & Madres Solteras & Adultos Mayores & Hogar \\
\hline $\begin{array}{l}\text { (1) Familia } \\
\text { Gil }\end{array}$ & \begin{tabular}{lr}
\multicolumn{3}{c}{ Tanto el padre como } \\
los hijos han \\
migrado a nivel \\
nacional \\
internacional, esto \\
con el fin de obtener \\
mejores ingresos. \\
En el caso de las \\
mujeres la \\
migración es local.
\end{tabular} & $\begin{array}{l}\text { Madres de familia } \\
\text { con hijos que } \\
\text { tiene que salir a } \\
\text { trabajar ya sea en } \\
\text { el comercio } \\
\text { informal o } \\
\text { bordando } \\
\text { servilletas. }\end{array}$ & $\begin{array}{l}\text { Los } \\
\text { mayores (abuelos) } \\
\text { cumplen con una } \\
\text { responsabilidad del } \\
\text { cuidado de los } \\
\text { nietos mientras los } \\
\text { hijos trabajan } \\
\text { durante el día } \\
\text { quizás durante la } \\
\text { semana. }\end{array}$ & $\begin{array}{l}\text { La familia tiene algunas } \\
\text { aves de corral para el } \\
\text { autoconsumo, tienen un } \\
\text { pequeño terreno donde } \\
\text { cultivan col, calabacitas, } \\
\text { habas, cebollas y } \\
\text { algunas zanahorias }\end{array}$ \\
\hline $\begin{array}{l}\text { (2) Familia } \\
\text { García }\end{array}$ & $\begin{array}{l}\text { El padre emigró } \\
\text { desde muy joven a } \\
\text { varias partes de la } \\
\text { república mexicana. } \\
\text { Los hijos salen a } \\
\text { trabajar a la Cuidad } \\
\text { de México. }\end{array}$ & $\begin{array}{l}\text { Dos madres } \\
\text { solteras que salen } \\
\text { a trabajar a la } \\
\text { ciudad de México } \\
\text { de empleadas } \\
\text { doméstica. }\end{array}$ & $\begin{array}{l}\text { Ambos abuelos se } \\
\text { quedan al cuidado } \\
\text { de los nietos. Las } \\
\text { hijas trabajan y van } \\
\text { a casa los fines de } \\
\text { semana. }\end{array}$ & $\begin{array}{l}\text { No tienen animales } \\
\text { domésticos como aves } \\
\text { de corral. Tienen } \\
\text { algunos árboles frutales, } \\
\text { como ciruelos. Cerca de } \\
\text { su casa tienen cultivos } \\
\text { de maíz. }\end{array}$ \\
\hline $\begin{array}{l}\text { (3) Familia } \\
\text { García }\end{array}$ & $\begin{array}{l}\text { De jóvenes ambos } \\
\text { padres trabajaron en } \\
\text { la Ciudad de } \\
\text { México, los } 6 \text { hijos } \\
\text { salen a trabajar } \\
\text { hacia varios estados } \\
\text { de la República. }\end{array}$ & $\begin{array}{l}\text { La familia tiene } \\
\text { una mujer mayor } \\
\text { de cincuenta años } \\
\text { que es madre } \\
\text { soltera con un } \\
\text { hijo. Trabaja en la } \\
\text { Ciudad de } \\
\text { México. }\end{array}$ & $\begin{array}{l}\text { Tanto el padre } \\
\text { como la madre, ya } \\
\text { pasan de los setenta } \\
\text { años. En ocasiones } \\
\text { cuidan a una nieta } \\
\text { de } \\
\text { aproximadamente } \\
10 \text { años. }\end{array}$ & 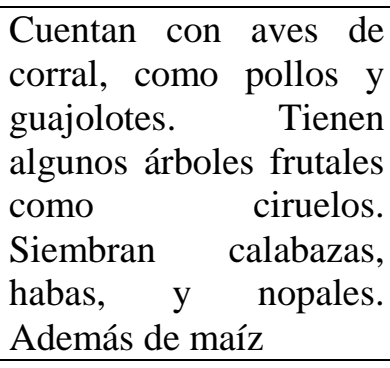 \\
\hline
\end{tabular}




\begin{tabular}{|c|c|c|c|c|}
\hline $\begin{array}{l}\text { (4) Familia } \\
\text { Solís }\end{array}$ & $\begin{array}{l}\text { Padres, hijos y } \\
\text { nietos han tenido } \\
\text { que emigrar de } \\
\text { manera temporal o } \\
\text { permanente. La } \\
\text { migración se da } \\
\text { tanto dentro del país } \\
\text { como hacia Estados } \\
\text { Unidos. }\end{array}$ & $\begin{array}{l}\text { En esta familia no } \\
\text { se presentaron } \\
\text { casos de madres } \\
\text { solteras (al menos } \\
\text { en los parientes } \\
\text { cercanos) }\end{array}$ & $\begin{array}{l}\text { Al parecer los } \\
\text { adultos mayores no } \\
\text { se hacen cargo de } \\
\text { los nietos. }\end{array}$ & $\begin{array}{l}\text { Tienen aves de corral, } \\
\text { alrededor de dos } \\
\text { decenas de borregos. } \\
\text { Cuentan con algunos } \\
\text { árboles frutales de } \\
\text { ciruelos. Tienen cultivos } \\
\text { de nopales, calabazas, } \\
\text { habas y maíz. }\end{array}$ \\
\hline
\end{tabular}

\begin{tabular}{|c|c|c|c|c|}
\hline $\begin{array}{l}\text { (5) Familia } \\
\text { Juárez }\end{array}$ & $\begin{array}{l}\text { Sólo hijas salieron } \\
\text { cuando eran jóvenes } \\
\text { a trabajar a la } \\
\text { Ciudad de México. }\end{array}$ & $\begin{array}{l}\text { La hija es madre } \\
\text { soltera y tiene tres } \\
\text { hijos. }\end{array}$ & $\begin{array}{l}\text { La madre ayuda a } \\
\text { la hija con los } \\
\text { quehaceres de la } \\
\text { casa, a hacer } \\
\text { comida para los } \\
\text { nietos y los } \\
\text { ingresos } \\
\text { obtiene del telar de } \\
\text { cintura ayuda con } \\
\text { los gastos de la } \\
\text { casa. }\end{array}$ & $\begin{array}{l}\text { Cuentan con aves de } \\
\text { corral para } \\
\text { autoconsumo, tienen } \\
\text { árboles frutales de } \\
\text { durazno y algunos } \\
\text { ciruelos. Siembran maíz. }\end{array}$ \\
\hline $\begin{array}{l}\text { (6) Familia } \\
\text { Díaz }\end{array}$ & $\begin{array}{l}\text { El padre emigró por } \\
\text { temporadas a la } \\
\text { Ciudad de México, } \\
\text { los hijos han } \\
\text { migrada ranto } \\
\text { dentro del país } \\
\text { como a Estados } \\
\text { Unidos. }\end{array}$ & $\begin{array}{l}\text { La hija menor de } \\
44 \text { años, es madre } \\
\text { soltera y tiene } 4 \\
\text { hijos. }\end{array}$ & $\begin{array}{l}\text { La madre de } 86 \\
\text { años ayuda a su hija } \\
\text { a cuidar a los nietos } \\
\text { mientras hija sale a } \\
\text { trabajar. }\end{array}$ & $\begin{array}{l}\text { La familia cuenta con } \\
\text { aves de corral, como } \\
\text { guajolotes y pollos. } \\
\text { Cultivan el maíz y } \\
\text { algunas veces haba. }\end{array}$ \\
\hline $\begin{array}{c}\text { (7) Familia } \\
\text { Juárez N. }\end{array}$ & $\begin{array}{l}\text { El esposo y los han } \\
\text { migrado a diferentes } \\
\text { estados dentro de la } \\
\text { República. }\end{array}$ & $\begin{array}{l}\text { En esta familia no } \\
\text { se obtuvieron } \\
\text { datos acerca de } \\
\text { madres solteras. }\end{array}$ & $\begin{array}{l}\text { En este caso tanto el } \\
\text { hombre como la } \\
\text { mujer, son adultos } \\
\text { mayores. Se aprecia } \\
\text { que los hijos están a } \\
\text { cargo de ellos. }\end{array}$ & $\begin{array}{l}\text { Se puede ver que aún } \\
\text { tienen algunas aves de } \\
\text { corral. Cultivan el maíz } \\
\text { para el autoconsumo. }\end{array}$ \\
\hline
\end{tabular}

Fuente: Elaboración propia con datos de trabajo de campo 2018

\section{DISCUSIÓN}

De acuerdo con lo que se pudo documentar en el lugar, a partir de los testimonios de los informantes, fue hacia la década de los setenta del siglo pasado cuando las familias de San Felipe Santiago empezaron a experimentar cambios más rápidos y tomar decisiones con mayor trascendencia, sobre todo en el aspecto económico. Esto es consistente con lo documentado en otras comunidades del pueblo otomí (Juan, Rebollar y Monroy 2007), en las que se muestra con claridad que "si en la década de los sesenta la actividad agrícola todavía permite la reproducción de las unidades de producción familiar de muchas zonas rurales del país, esta realidad cambia notablemente hacia finales de los ochenta y las dos 
décadas siguientes" (Mora 2018, 82). Lo que además esos mismos datos presentados antes permiten deducir es que las decisiones fueron imprevistas; no son procesos planeados y, sin embargo, detonaron transformaciones radicales al interior de las familiares y la comunidad. No obstante, eso no debería tomarse esto como una revolución, una ruptura, una superación o desecho de lo anterior.

Dicho en otras palabras, cuando los habitantes de esta comunidad toman la decisión de ya no sembrar la tierra como medio de subsistencia, para ahora migrar, aprender un oficio o poner un negocio (lo cual incluye en algunos casos vender o fraccionar la tierra para entregarla a los hijos o descendientes), están tomando otra ruta para articularse al mundo: toman de su entorno elementos diferentes para re-organizar su vida. Y, sin embargo, este reordenar, este relacionar elementos incluye los que aparentemente quedan atrás: la tierra sigue ahí, quizá ahora la siembran para autoconsumo y nada más, pero ahora está agrupada con el negocio familiar, con los tiempos de la migración laboral, incluso con los estudios o los aprendizajes de oficios. Hay una reorganización en la que los elementos pueden permanecer y estar vinculados bajo un nuevo modo de relación. Dos botones de muestra: "Mi esposo trabaja en una fábrica de productos químicos en la Ciudad de México, aunque también se dedica al campo en las temporadas, cuando hay que sembrar el maíz... Cuando se cosecha se viene a trabajar acá" (Carmen, 41 años); "llevo alrededor de veinte años con la lonchería, es como la tienda escolar... También trabajo en el campo cuando hay que sembrar, se cultiva maíz, es de regadío" (Abel, 64 años).

Sí, es notorio también que en la segunda mitad del siglo XX esta comunidad experimentó una paulatina expansión del movimiento pentecostés (en detrimento del catolicismo de raigambre colonial en la región), y ello también remite a una discontinuidad que supone, en cada generación, incorporar algo que no estaba en la anterior: la gente que va moviéndose a esta práctica religiosa como decisión personal/familiar. Por eso es necesario tomar en cuenta este elemento introducido desde el entorno (la gente habla de norteamericanos que llegaron a predicar), pero que en la memoria común toma sentido por contraste con el pasado católico en el que las cosas no iban tan bien: "Queriendo hacernos un mal, nos hicieron un bien; la gente tomó lo bueno de la religión que ellos trajeron. Se tomó lo que sirve: hay más unidad con las familias, la gente se dedica a trabajar y no a emborracharse". 
Lo mismo podría sugerirse con el desplazamiento lingüístico: el otomí fue desplazado casi por completo, pero no tanto por voluntad (así es como resulta re-pensado por los informantes), sino por obligación, coacción o demanda: los maestros, los papás, la "gente de fuera" los orilló a dejar de hablar. Pero el explicar la pérdida de la lengua materna en relación con esos episodios de discriminación, por ejemplo, otorgan sentido al presente en relación con el pasado. Al menos a la lengua no se le asigna la etiqueta de arcaísmo que había que superar, sino de elemento propio que tuvo que dejarse, pero que sigue siendo parte "de lo que éramos" y, de algún modo, siguen siendo. No es la idea del pasado superado, sino la idea del pasado que sigue indicando de dónde se viene.

En los domicilios de las familias tomadas para el estudio vimos un uso extendido de los teléfonos celulares, pero también estaban ahí el telar de cintura y el metate para hacer las tortillas; en todas las casas había televisión y dispositivos electrónicos diversos, pero en muchas compartían el espacio con gallinas y guajolotes que se crían desde siempre para autoconsumo. Un mosaico así sólo es muestra material de "acciones politemporales", porque "somos intercambiadores y mezcladores de tiempo. Es ese intercambio el que nos define" (Latour 2012b, 113).

Lo común sería mencionar que los elementos tradicionales con que cuenta la comunidad son su identidad étnica otomí, su lengua, la religión católica y cierta actividad agrícola. Pero los datos obtenidos durante la investigación justifican decir que todos esos elementos están re-compuestos, re-organizados bajo una temporalidad que los re-une con elementos nuevos: experiencias en la ciudad, actividades comerciales, migración internacional, gustos y prácticas de nuevo cuño, que han sido incorporadas en "el camino", con el paso de los años, generación tras generación, a partir de selecciones nuevas de elementos presentes en un entorno no sólo cambiante sino más amplio y complejo.

Cuando Latour, al re-leer a Darwin, sugiere que entre cada ser y el siguiente existe una discontinuidad vertiginosa que supone, en cada generación, una invención única y singular, deja espacio para pensar en las decisiones que cada generación de la comunidad de estudio tomó (migrar, cambiar de religión, ocupación, etc.), pero que no anulan definitivamente todo "lo demás", sino que bien pueden articularse en una temporalidad en la que se une lo que ahora es con lo que fue, o también en un espacio donde se encuentra lo que ahora se usa, pero junto con otros objetos que se venían usando desde que se tiene memoria. Si se 
prefiere este término, puede decirse que "fusionan" elementos tradicionales y modernos que la gente articula porque les facilitan la vida cotidiana.

Hoy en la comunidad, como consecuencia de la mejora en caminos y carreteras, es inherente la presencia de taxis, microbuses, camiones, motocicletas, además de que la mayoría de familias ya cuentan con un vehículo particular. Están casi generalizados los servicios de luz, agua potable, telefonía, Internet, televisión por cable. Pero, de manera simultanean, está todavía esa gente que borda con técnicas ancestrales y a la que los vecinos le hacen pedidos para rituales festivos. En la casa de estas personas están la computadora y el teléfono celular al lado del telar para tejer el mecapal (esa especie de faja de origen prehispánico). Son continuidades de un tipo muy especial.

La noción de "discontinuidad", que se dijo desde el principio de este artículo que se buscaba explorar, toma un sentido específico a la luz de lo que la evidencia recabada permite asegurar: en la vida de las personas se restablece la continuidad más allá del concepto estático de "tradición". Sus selecciones se mantienen activas e incluyen elementos pertenecientes a diferentes tiempos, a distintas generaciones. Esto ocurre no sólo en los hechos, sino en la memoria. En los hechos, uno puede ver esos espacios y dinámicas donde conviven los empleos y los servicios con las actividades agrícolas; o puede apreciarse en las calles del lugar a jóvenes influidos por las tribus urbanas (tras migrar con fines laborales) vestirse como punk y cruzarse en el camino con ancianas que visten a la usanza tradicional otomí.

$\mathrm{Y}$ en lo que hace al argumento discursivo (que se buscó recolectar a través de las conversaciones con la gente), uno puede ver el tipo de recuerdos que éste puede detonar: el principio de incertidumbre que opera, por ejemplo, cuando de entre las muchas posibilidades discursivas que ellos pueden desarrollar acerca de lo ocurrido con su lengua a lo largo de los años llama mucho la atención. Se erigen como detonaciones narrativas proveedoras de sentido el recuerdo de los profesores que les prohibían hablar en otomí o los papás que les pegaban para que no hablaran su lengua. Ellos crean en la memoria colectiva un pasado en el que hubo responsables por la pérdida. Todo esto se mantiene presente, articulado en posibilidades argumentativas, vivenciales, existenciales y emotivas (Pérez-Taylor 2002), como se sugirió al principio.

En lo que hace a la noción de ambiente, en el sentido de creación que cada ser vivo hace a partir de elementos del entorno. Se asumió desde el inicio del trabajo que el ambiente de 
un organismo es el conjunto de condiciones exteriores que para él tienen alguna relevancia, porque el organismo interactúa con esos aspectos del mundo exterior" (Lewontin 2017, 57). Los datos recolectados mediante el trabajo de campo dejan ver una etapa en la comunidad (posterior a la Revolución y al reparto de tierras) durante la cual la tierra era un elemento fundamental en el ambiente de sus pobladores. En esa etapa el cultivo de sus propias parcelas y la cría de algunos animales domésticos proporcionaron a los campesinos otomíes recursos suficientes para el autoconsumo. El principal cultivo era el maíz, pero también se cultivaba el trigo, la cebada, frijol, calabaza, entre otros; además se criaban aves de corral, ovejas, cerdos, vacas etc. Ambos fueron elementos ambientales que en su momento forjaron un tipo de conexiones entre los individuos y entre éstos y su entorno que puede caracterizarse como "vida campesina", soportada en unidades económicas familiares no asalariadas. Hoy en día es claro que la tierra sigue ahí, los bosques (aunque cada vez más diezmados) también están ahí, lo mismo que los ríos, cerros y valles, pero ¿cómo se relacionan con ellos?, ¿qué lugar de importancia tienen para la subsistencia?

Los datos registrados durante la aproximación etnográfica a la comunidad arrojaron que las principales fuentes de ingreso monetario de los hogares en esta comunidad son ahora las actividades terciarias, como el comercio y los servicios. Hay una serie de ajustes en la organización de los elementos del entorno que ahora conforman el ambiente, y esto es coincidente con otros trabajos realizados en la zona, en los que se registró que "tales ajustes se realizan, en un primer nivel, al interior de cada familia; luego, en un segundo nivel, sea por imitación o por compartir las mismas circunstancias, grupos de familias coinciden en ellos, y finalmente, llegamos al nivel en el que los ajustes se reflejan en toda una comunidad (Arriaga 2019, 81).

Los principales ajustes pueden resumirse en que cada familia ha insertado a alguno(s) de sus integrantes en el mercado laboral; esta estrategia sigue el mismo patrón de solidaridad característico de la familia campesina. Los ingresos monetarios en ocasiones son tomados como "complementarios" (aunque en realidad sen lo que sostienen la vida cotidiana), porque la actividad agrícola sigue marcando ritmos y tiempos. Hay importantes cambios en el gusto y en el consumo: los alimentos procesados, así como bienes y servicios que son propios de la vida urbana, han sido incorporados a la cotidianidad de las familias. Hay un nuevo tipo de ambiente en el que los flujos desde el exterior son más nutridos y constantes. Ello es consistente también con lo documentado en otras localidades con investigaciones 
similares (Arriaga, Morrongo y Mendoza 2020) que muestran cómo se incrementa la complejidad de las familias indígenas-campesinas.

También hubo un tiempo en la vida de la comunidad de estudio en el que la lengua otomí fue el único idioma que hablaban sus habitantes. Éste jugó un papel importante en la transmisión de aspectos culturales heredados de sus antepasados, como la medicina tradicional (que incluye la herbolaria), el tejido de algodón en telar de cintura, el procesamiento del ixtle utilizado para tejer ayates y costales para contener el maíz, los rituales agrícolas, los huertos familiares, entre otros. Los datos recabados sugieren que la lengua sigue teniendo un lugar en la comunidad, aunque éste se ubica menos en la práctica y más en la memoria colectiva. Aun así, no puede darse por "superado", más bien, como se ha logrado documentar para otros grupos indígenas en el estado de México, "La lengua aun no muere, pues "hay hablantes, aunque mochitos y sólo sepan 10 palabras pero los hay. Y no va a morir del todo mientras sea recordada (aunque no usada)" (Encarnación y Arriaga 2021: 24).

En suma, la investigación nos ha mostrado una comunidad viva, con una continuidad renovada a partir de un constante fluir de información, de personas que salen para luego traer a su lugar de origen recursos económicos, nuevas formas de pensamiento, de organización familiar y social. Influidos por ello, los habitantes incorporan cada vez más elementos a su ambiente provenientes de un entorno cada vez más amplio. Los nuevos y los que ya estaban son re-organizados de formas muy diversas. Esto hace de las familias y de la propia comunidad algo renovado, totalmente diferente y no no necesariamente en la lógica del pasado superado.

\section{CONCLUSIÓN}

Una forma de estudiar la vida en las comunidades es no asumiendo apriorísticamente y a la distancia su existencia, sino documentar su generación a partir de las conexiones que la sostienen. Esas conexiones no sólo son las que producen sus habitantes, sino que se extienden al entorno, del que seleccionan elementos (humanos y no humanos) con los que entablen relaciones significativas. Hubo un tiempo en el que en San Felipe Santiago esas relaciones eran muy limitadas y los elementos del entorno que pasaban a formar parte de su ambiente eran básicamente la tierra, el bosque, los animales, el agua y nada más. Con el paso del tiempo estos elementos han sido re-ubicados y re-organizados dentro de dinámicas 
que animan una vida más compleja, por el número de elementos del entorno que forman parte del ambiente.

La vida cotidiana siempre les impone la necesidad de ir haciendo ajustes, los cuales suelen ser contingentes y sus consecuencias imprevistas. Las decisiones de mayor importancia llevadas a cabo por las familias estudiadas son las siguientes:

- El desplazamiento de la lengua otomí, que hoy es más recordada que hablada; es más un elemento identitario de la memoria colectiva que una herramienta en la vida social.

- Articular las actividades agrícolas con otras labores productoras de ingresos como el comercio informal o formal, la migración con fines laborales y la prestación de servicios dentro y fuera de la localidad. En esta articulación la labor agrícola ocupa un plano más bien secundario o complementario.

- El abandono de la religión católica para adoptar en su lugar el pentecostalismo, que, en la mayoría de las familias convertidas, ha servido como estímulo para enfrentar los cambios socioculturales que se han venido dando en las últimas décadas.

La discontinuidad que podría advertirse entre generaciones al interior de la comunidad rural-indígena de San Felipe Santiago se presenta, tras la aproximación etnográfica realizada, como una continuidad re-novada, más allá de más allá del concepto estático de “tradición” y sin corresponderse a la noción del pasado superado.

\section{REFERENCIAS}

Arriaga, José Luis. 2019. “Pobreza, adaptación sociocultural al ambiente y autoreproducción de la familia campesina en México". Episteme. 11, 1: 65-83. https://revistas.usantotomas.edu.co/index.php/episteme/article/view/5587/5515

Arriaga, José Luis y Rodrigo Marcial. 2017. "Contingencia y reensamblado social entre los jóvenes seguidores de 'El Camino Rojo' en México". Pilquen 20, 4: 41-55. http://revele.uncoma.edu.ar/htdoc/revele/index.php/Sociales/article/view/1789/1826

Arriaga, José Luis, Nancy Morrongo e Irvin Mendoza. 2020. “Sembrar la tierra para seguir siendo: mecanismos adaptativos de auto-reproducción de la forma de vida en comunidades indígenas rurales del Estado de México”. Ketzalcalli, I, 2020: En prensa.

Darwin, Charles. 1982. Origen del hombre. México: Editores Mexicanos Unidos.

Dubet, Francois. y Danilo Martuccelli. 2000. ¿En qué sociedad vivimos? Buenos Aires: Losada.

Durkheim, Emile. 1982. Las formas elementales de la vida religiosa. Madrid: Akal. 
Encarnación, Xochiquetzal y José Luis Arriaga. 2021. "Decían que contestábamos como pípiles”. Memoria colectiva y pérdida de la lengua tlahuica en San Juan Atzingo, Ocuilan, Estado de México. Diario de Campo, 7, 2021: En prensa.

Encino, Vanessa., Ana Cristina Flores, Yesica Miranda y José Luis Arriaga. 2020. “Tortillas 'hechas a mano': trabajo domiciliario femenino emergente en el barrio de San Martín, Malinalco, Estado de México". Revista Latinoamericana de Antropología del Trabajo. 4, 9: 1-27. http://www.ceil-conicet.gov.ar/ojs/index.php/lat/article/view/672

H. Ayuntamiento de Jiquipilco (2019). Plan de Desarrollo Municipal 2019-2021. https://www.jiquipilco.gob.mx/files/plan-de-desarrollo-2019-2021.pdf

Juan, José Isabel, Samuel Rebollar y José Francisco Monroy. 2007. “Descampesinización de una comunidad indígena campesina en México. Un estudio para comprender la articulación del modo de producción simple con el sistema de producción capitalista”. Revista de académica economía. https://www.eumed.net/cursecon/ecolat/mx/2007/prm.htm

Latour, Bruno. 2008. Reensamblar lo social: una introducción a la teoría del actor-red. Buenos Aires: Manantial.

Latour, Bruno. 2012a. Gogitamus. Buenos Aires: Paidós.

Latour, Bruno. 2012b. Nunca fuimos modernos. Ensayo de antropología simétrica. Buenos Aires: Siglo XXI.

Lewontin, Richard. 2017. Genes, organismo y ambientes: las relaciones de causa y efecto en biología. México: Gedisa.

Mora, Libertad. 2018. "Nueva ruralidad en la Huasteca poblana: otomíes y nahuas de Pahuatlán (1960-2010) Relaciones. Estudios de historia y sociedad, 39, 154: 71-136. https://www.redalyc.org/jatsRepo/137/13758018004/html/index.html

Pérez-Taylor, Rafael. 2002. Antropología de la complejidad. México: Gedisa.

Riquelme, Elizabeth, Aransazú Rojas y Andrés Jiménez. 2012. "Equilibrio trabajo-familia, apoyo familiar, autoeficacia parental y funcionamiento familiar percibidos por funcionarios públicos de Chile”. Trabajo y Sociedad, XVI, 18: 203-215. https://www.redalyc.org/articulo.oa?id=387334690013

Sandoval, Eduardo. (1997). "Familia indígena y unidad doméstica: los otomíes del Estado de México". Papeles de Población, 2 (marzo-abril): 50-64. 
Steward, Julian. 1955. "El concepto y el método de la ecología cultural”. En Clásicos y Contemporáneos en Antropología, CIESAS-UAM-UIA. https://www.ciesas.edu.mx/publicaciones/clasicos/00_CCA/Articulos_CCA/CCA_PD F/040_STEWARD_1955_El\%20Concepto_yel_metodo.pdf

Subuyuj, Wendy. (2013). Adaptabilidad social de un grupo de auditores que laboran en distintas empresas de la Ciudad de Guatemala. Campus Central Guatemala. [Tesis de grado Universidad Rafael Landívar]. http://biblio3.url.edu.gt/Tesario/2013/05/43/Subuyuj-Wendy.pdf

Velasco, Juan Jesús. 2002. Subsistencia campesina y desarrollo sustentable en la región monarca. Toluca: Universidad Autónoma del Estado de México.

Von Uexküll, Jacob. 2016. Andanzas por los mundos circundantes de los animales y los hombres. Buenos Aires: Cactus. 